\title{
sala preta
}

ppgac

\section{O performer insurgente da cena: performances de um corpo diferenciado}

The insurgent performer of the scene: performances of a differentiated body

Felipe Henrique Monteiro Oliveira

Felipe Henrique Monteiro Oliveira Fundador do Centro Internacional de Pesquisas Artísticas e Acadêmicas sobre Antonin Artaud. Pós-doutorando no Programa de Pós-Graduação em Artes Cênicas da Universidade de São Paulo (USP). Bolsista pela Coordenação de Aperfeiçoamento Pessoal de Nível Superior. Doutor em Artes Cênicas pela Universidade Federal da Bahia (Ufba)

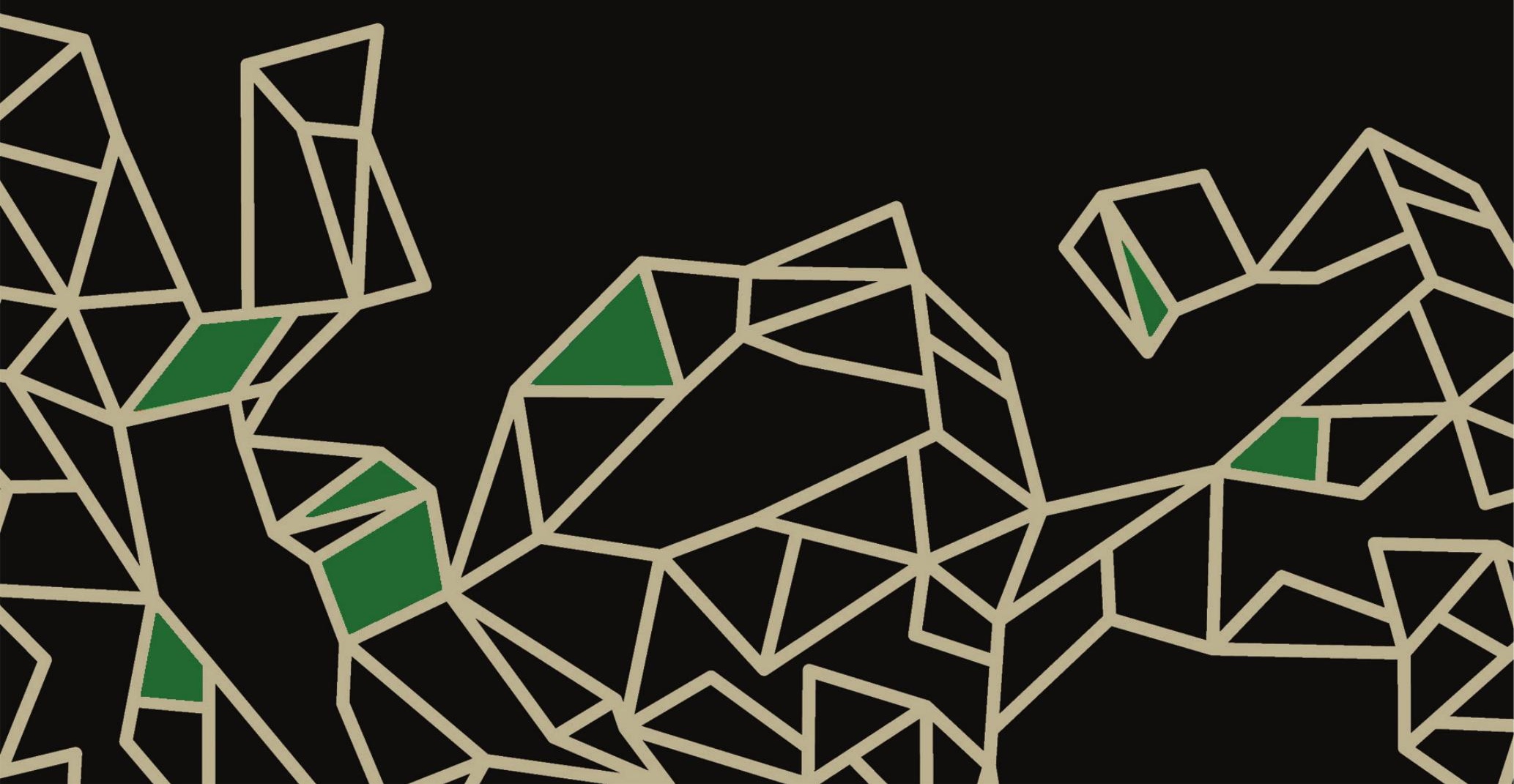




\section{Resumo}

Este artigo reflete sobre o performer como um insurgente: quando está em cena, esse artista tenta encontrar um elo entre arte e vida, e não a sua separação, pois passa a assumir através da presença de seu corpo a função de ser sujeito, objeto e trajeto de arte na efemeridade de sua performance.

Palavras-chave: Corpos diferenciados, Performer, Performance, Artivismo, Insurgências.

\section{Abstract}

This article reflects on the performer as an insurgent on the scene since the artist tries to connect art and life during each performance, not separate both, as they begin to assume the function of being subject, object and art trajectory in the temporary nature of the body's performance.

Keywords: Differentiated bodies, Performer, Performance, Artivism, Insurgencies.

Nos dias atuais, muitos são os estudos que conjecturam acerca das teorias e práticas que balizam as funções exercidas pelos profissionais que fazem parte, pensam e produzem o fazer cênico contemporâneo. Este estudo enfatiza o papel do performer na cena, em especial dos performers com corpos diferenciados ${ }^{1}$, sobretudo quando o sujeito artivista compreende a política como performance e passa a assumir o que defino como a função de insurgente em seu fazer performático.

A performance comunga com os ideais do artivismo², uma vez que a maioria dos performers e de seus fazeres performáticos não se filia a uma política partidária, mas se engaja politicamente em diferentes propósitos. Esse fazer cênico se mistura com as ideias da contracultura e com a indagação de que o performer é um artista insurgente, haja vista que se insurge na arte e na vida contra tudo e todos que preconizam discursos e práticas

1 O termo corpos diferenciados foi cunhado por mim (OLIVEIRA, 2013) e Nara Salles (OLIVEIRA; SALLES, 2018) para designar as pessoas com deficiência.

2 O artivismo intervém nos contextos e nas situações cotidianas com a premissa de utilizar a arte para fazer política e reconhece esta como uma forma de arte também. 
totalitárias excludentes e produtoras de estigmas sobre as pessoas com corpos diferenciados.

Para Diana Taylor (2011; TAYLOR; FUENTES, 2012), o performer, estando inserido cotidianamente em ações que transitam entre as diversas dimensões da vida humana, compreende a política como performance e usa a arte para fazer política, podendo direcionar a sua obra para as discussões e práticas relativas aos estratos público e privado, objetivando realizações que mudam os diferentes contextos da realidade, ou seja, a arte se torna artivista.

O performer assume o papel de artivista quando se dispõe de forma crítica e não alienada a insurgir contra os sistemas de poder totalitários que colocam os indivíduos longe das próprias decisões concernentes aos modos de viver e ser na realidade em que se encontram. A definição de insurgência referida aqui não faz nenhuma apologia ao terrorismo, aproximando-se mais das ideias da contracultura, pois, segundo Ken Goffman e Dan Joy (2007, p. 12), "as contraculturas buscam basicamente viver tão livres das restrições à força criativa quanto seja possível, onde e como quer que seja possível fazê-lo".

A performance explode as convenções socioculturais e artísticas que restringem e censuram os trabalhos de artes explicitamente corporais na sociedade capitalista; ela não deve pedir licença para existir: ela implode o próprio paradigma artístico, pois não se priva de se realizar diante de julgamentos e entendimentos autoritários que pretendem julgar o que é ou não arte. O triunfo da performance perante o reacionarismo é atribuído a sua característica de expor, por diferentes formas cênicas, as artimanhas que alienam as pessoas sobre a liberdade de seus próprios corpos em diversos contextos da vida e da arte.

O performer não quer mais representar, mas se presentar. Ele pode até explanar algum texto em cena durante seus solos e monólogos, porém de forma não dramática, pois visa substanciar a sua arte performática através de seus espectros autobiográficos. Em vista disso, a performance possui infinitas variáveis e é feita por artistas inconformados com as limitações exercidas pelas expectativas normativas da sociedade e que querem colocar sua arte em contato direto com o público. Na ação performática, não apenas o íntimo do artista está vindo à tona, mas também o público: o performer é autor, matéria-prima e objeto artístico da sua obra, e frequentemente revela aos 
espectadores o anacronismo das artimanhas políticas, sociais e culturais da sociedade em que vivem.

A performance se configura como uma arte contracultural que não pretende e não quer se integrar ao normativo, mas se rebelar e transgredir o que está estabelecido. Ela envolve, de forma não hierárquica, a participação de todos que estão no ato performático; prioriza a simplicidade ou a extinção dos aparatos cênicos; permite que o performer seja autêntico e aja de acordo com suas ações pessoais e inclinações políticas não partidárias; e intensifica o embasamento dos territórios e das fronteiras da arte e da vida.

A performance no contexto cênico contemporâneo não se filia à arte tradicional, por não produzir formas fixas nem se destinar ao mercado de arte; ao contrário, refuta e se insurge contra um fazer artístico reservado a grupos elitizados - os consumidores de obras de arte. Para Peggy Phelan (1993), a ontologia da performance reside na representação sem reprodução, ou seja, a principal característica da performance é o seu acontecimento único e efêmero, definido a partir da sua singularidade, e não das tentativas de reproduzi-lo. Para a pesquisadora estadunidense (Ibid.) a performance se diferencia das outras linguagens artísticas por não permanecer como um objeto artístico, mesmo se utilizando de diferentes mídias reprodutivas.

O performer deseja ser o sujeito que, por meio do seu corpo, se insurge contra si mesmo para friccionar e exibir as fraturas de seu tempo, pois bem sabe que sua insurgência pertence ao tempo hic et nunc da sua vida. Seu pensar-fazer performance busca questionar, subverter e transgredir os desafiadores e instigantes preceitos defendidos pelo establishment da racionalidade totalitária e tecnocrata de nosso tempo.

Em outras palavras, o performer se torna um indivíduo que não consegue nem quer se adaptar às exigências e ao anacronismo de sua época, embora saiba que, de toda forma, não pode fugir da razão de pertencer singularmente ao seu tempo. Para tal empreitada, pode-se afirmar que a performance é uma arte do eu, como defende Josefina Alcázar (2014). O performer utiliza seu próprio corpo para dizer em primeira pessoa não somente sobre as questões públicas, mas especialmente para expor sua privacidade ao coletivo.

Em sua performance, o artista assume uma posição política, isto é, afirma uma posição de recusa, de repulsa e de protesto diante do establishment. 
Os performers intentam a insurgência e o artivismo em cena porque têm a preocupação de produzir uma arte contestadora dos discursos e das práticas homogeneizantes. O próprio ato de pensar-fazer performance demanda de imediato do performer uma vontade de ser heterogêneo e autêntico em sua prática, principalmente exercendo o direito de dizer através de sua arte que todos os presentes na cena podem se insurgir perante a alienação em que vivem.

Nesse contexto, em minha pesquisa de doutorado (OLIVEIRA, 2018) pelo Programa de Pós-Graduação em Artes Cênicas da Universidade Federal da Bahia (PPGAC/Ufba), estabeleci aproximações entre o pensamento de Artaud (2006) e suas reverberações na performance, pois percebi as seguintes proposições e ligações entre as duas formas de encenação: (1) ampliar as fronteiras da realidade na qual se faz o exercício da vida; (2) buscar fazer e estabelecer elos entre arte e vida, e não separá-las; (3) desorganizar aparências, derrubar preconceitos e fazer emergir verdades secretas e não imaginadas, provocando no espectador uma recepção muito mais cognitivo-sensorial do que racional; (4) produzir imagens físicas violentas, baseadas na ideia de ações extremas que provoquem os sentidos e a alma do espectador; (5) provocar nos participantes um desejo de mudança; (6) produzir cenas ritualísticas, permeadas pela emoção e, principalmente, centradas no corpo do atuante e em tudo que apele aos sentidos do espectador, renegando dessa forma a dogmatização do texto dramático como regente supremo do fazer teatral.

Artaud pode ser considerado um precursor da performance pois, ao não separar a arte da vida, suas ideias ainda servem como potenciais influências para os estudiosos e os praticantes dessa arte cênica híbrida e cruel, que busca não apenas uma independência da cena perante a literatura dramática e a feitura de obras-primas, mas, sobretudo, contagiar mudanças existenciais na vida daqueles que dela participam. As reverberações das ideias de Artaud (Op. cit.) permeiam e se instauram nas seguintes performances que realizei: (DES)VITRUVIANDO (2014), Sanguis (2014) e Reliquiarium experientiis (2014).

\section{(DES)VITRUVIANDO}

Apresentei a performance (DES)VITRUVIANDO no ano de 2014, em Salvador (BA): forrei com papéis brancos o chão da sala da galeria Cañizares, 
na Ufba, para que, com canetas hidrográficas coloridas dispostas pelo espaço, os espectadores desenhassem ou escrevessem o que quisessem no papel em que estava deitado. Esse título foi escolhido pois o objetivo artístico principal era mostrar em cena as desproporções e as limitações físicas decorrentes da degeneração do corpo diferenciado do encenador, além de proporcionar aos espectadores a oportunidade de desfazerem seus zelos exagerados diante de um corpo com deficiência. A apresentação tencionou expor a anatomia e a fragilidade do corpo diferenciado, opondo-se assim à ideologia vindoura de outros séculos que representa as proporções e os ideais de corpo perfeito - figurado, por exemplo, no desenho Homem vitruviano do artista italiano renascentista Leonardo da Vinci, feito por volta de 1490.

Essa obra foi criada para se configurar como uma cerimônia ritualística em que o corpo diferenciado está no centro do espaço liminar permeado pelas forças energéticas emanadas pelos espectadores. Vesti apenas uma cueca e pedi que alguns espectadores me pegassem nos braços para depois me deitarem no centro de um quadrado feito com papéis brancos, fixados com fita adesiva; em seguida, solicitei aos espectadores que, se quisessem, pegassem qualquer caneta hidrocor disposta nos papéis para contornar meu corpo diferenciado ou para desenhar e escrever qualquer coisa relacionada à apreciação da performance.

Ao expor a degeneração do corpo diferenciado causada pela progressão da amiotrofia espinhal progressiva, dispus-me seminu no espaço cênico com o objetivo de chacoalhar, semelhante à peste artaudiana (ARTAUD, Op. cit.), as angústias e a lembrança da finitude humana dos espectadores que participavam ativamente da performance, e até mesmo daqueles que apenas observavam a fragilidade e a pouca mobilidade daquele corpo deitado sobre o tapete de papel.

No decorrer da performance, tive a oportunidade de criar uma dança improvisada com Ciane Fernandes e Susanne Ohmann, na qual exploramos as proporções e as desproporções dos corpos no espaço e experienciamos as cinesferas individualmente e em grupo, havendo uma troca afetiva. Sendo assim, em cena demonstrou-se que "não podemos conceber uma harmonia excludente e unipolar - baseada em 'boas proporções do corpo humano' e em uma 'forma sem mistura' -, mas sim, por definição, inclusiva e múltipla" (FERNANDES, 2006, p. 342). 


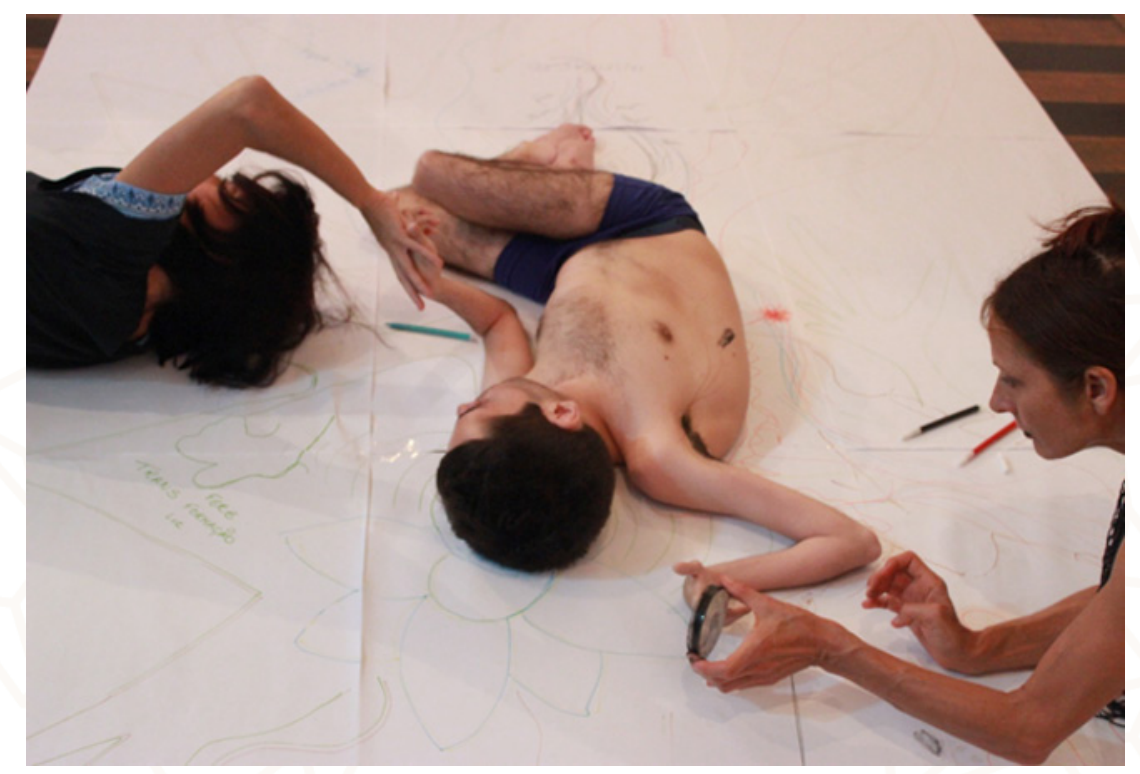

Figura 1 - Ciane Fernandes, Felipe Monteiro e Susanne Ohmann na performance (DES)VITRUVIANDO

Foto: Luis Carneiro Leão (2014)

Na performance (DES)VITRUVIANDO, não disfarcei em nenhum momento a atrofia de meus membros, a pouca mobilidade, a severa escoliose que faz com que minha coluna em formato espiralado dificulte a respiração, os suores e os odores do meu corpo diferenciado em cena, em um ato que não distingue a arte e a vida, perfazendo nos espectadores durante a interação performática a afirmação de que, no paradigma ontológico, todos os seres humanos são deficientes, porque incompletos, e fisiologicamente todos os corpos, a cada segundo, vão ao encontro da principal certeza existencial: a finitude humana.

\section{Sanguis}

A performance Sanguis ${ }^{3}$ foi apresentada no dia 15 de outubro de 2014 em frente à fonte da Escola de Teatro da Ufba. Nesta obra, com o objetivo de provocar sinestesias ${ }^{4}$, escolhi elaborar uma dramaturgia composta

3 "Sanguis" significa sangue, em latim.

4 Por sinestesia compreende-se a percepção do mundo por meio da relação subjetiva provocada espontaneamente pelos sentidos. Por exemplo, em Sanguis, os incensos possibilitaram evocar nos espectadores memórias relacionadas a imagens, paladares, sensações e/ou sons, fazendo com que o indivíduo fosse atravessado por emoções provenientes das produções de sentidos difundidos em cena. 
pelo som de meus batimentos cardíacos, gravados a partir de um exame de ecocardiograma; pelos diálogos com os espectadores; e pela participação destes, ao pedir-Ihes que vestissem luvas descartáveis, pegassem uma agulha, furassem meus dedos, desenhassem com o sangue em um pano branco e, por fim, acendessem e alocassem, em qualquer lugar do espaço, dois incensos.

$\mathrm{O}$ ato de pedir que os observadores furassem meus dedos e desenhassem o com o sangue no pano branco intentavam ressignificar momentos de minha vida em que eu era constantemente internado e via meu sangue nas agulhas, bem como a rejeição a qualquer tipo de vestimenta dos profissionais de saúde, principalmente se fosse da cor branca.

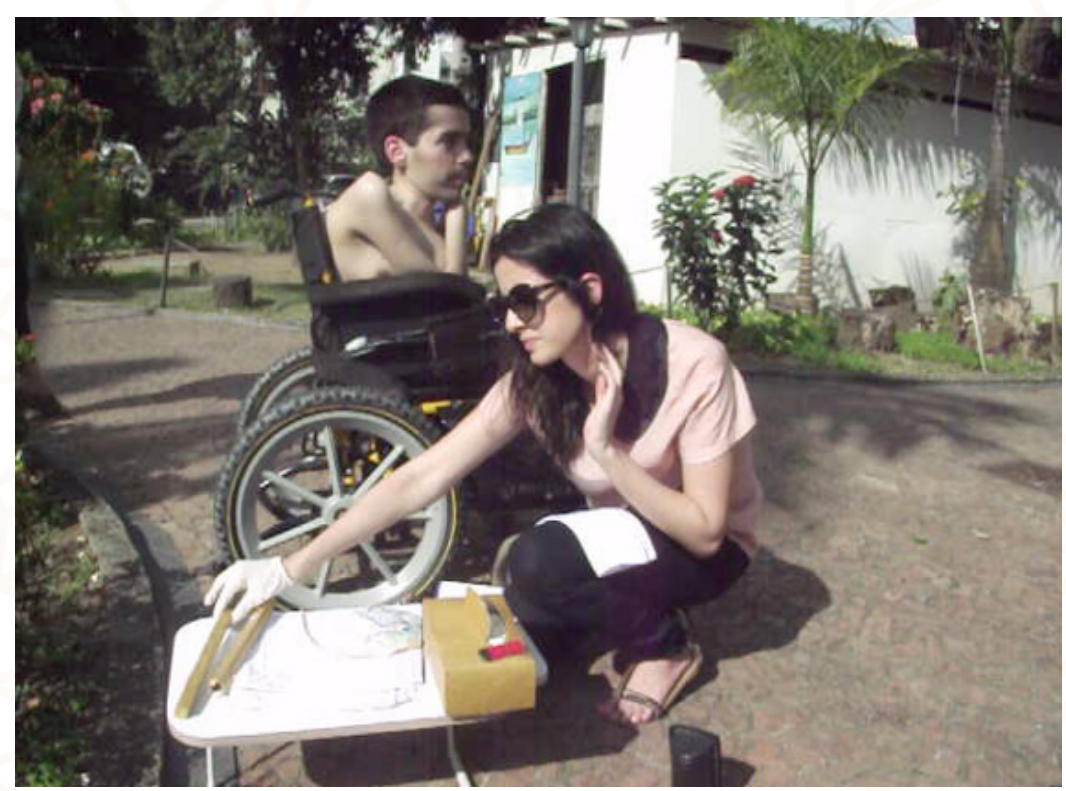

Figura 2 - Felipe Monteiro em Sanguis

Foto: acervo de Felipe Monteiro (2014)

Após o começo da performance, ao solicitar que os espectadores furassem meus dedos e desenhassem com o sangue em um pano branco, eles se assustavam - alguns furavam, outros não - e perguntavam: "Como a gente faz? Está doendo? Está machucando? Em qual parte do corpo devo pegar com mais cuidado?". Dessa forma, estabeleceu-se um diálogo com os participantes, proporcionando-Ihes a oportunidade de fazer parte da cena, pois havia um espaço cênico partilhado no qual poderiam abrir suas percepções para entender a tessitura dos elementos da obra. 
Nesse contexto, a francesa Florence de Mèredieu, historiadora da arte e especialista em Antonin Artaud, ao apreciar o vídeo da performance Sanguis fez a seguinte ponderação:

As pessoas que se aglomeram em torno dele e participam do ritual "hospitalar" (poderíamos interpretar sobre os diferentes sentidos deste termo que designa ao mesmo tempo o mundo médico e a dimensão de acolhimento dos "Anfitriões") se inquietam com os protocolos a seguir para abordar e "cuidar" deste corpo diferente. O sangue que corre sobre o tecido branco (símbolo e sintoma deste ambiente médico que é o pano de fundo do universo de Felipe Monteiro) também assusta. Relembrando, em tudo, sua função vital e sagrada ao mesmo tempo: "Sanguis Brasil".

Felipe Monteiro percebe as reações do público, divide em dois grupos: os que intervêm e os que observam. Os que agem receiam machucá-lo, perguntam-se como cuidar da melhor forma possível deste corpo em que a fragilidade Ihes assusta. O medo, a inquietação! Saímos aqui do ambiente puramente hospitalar. Entramos na esfera da partilha e da osmose... teatral, performativa. Mundo de emoções, de sensações, de sentimentos. Desenho do sangue sobre a tela do tecido. (MĖREDIEU, 2018, p. 259)

Sanguis permitiu que os participantes vivenciassem espacial, corporal e afetivamente uma relação direta com meu corpo diferenciado em cena, possibilitando aos espectadores um processo de autoexperiência e autorreflexão tanto na vida quanto na arte. A performance, enquanto processo artístico ritualístico, dá a oportunidade a cada espectador de perceber que, quanto mais se participa do ato, mais é possível notar que sua experiência não depende somente de si, pois, quando inserida em uma situação social, a experiência passa a depender de todos os envolvidos.

Na realização de Sanguis, as fronteiras e os territórios da arte e da vida foram embaraçados, visto que estão entrelaçados e não são dissociáveis pois, através da dor provocada pelo furo da agulha e pelo gotejamento do sangue, me coloquei em cena como um performer que expõe a lucidez de saber as limitações físicas de sua doença e de sua necessidade vitalícia de ser cuidado pelos outros em suas atividades diárias e fisiológicas, remontando às numerosas internações desde minha tenra infância. 
Durante a performance, não apenas consegui evocar a peste artaudiana (ARTAUD, Op. cit.), mas me tornei a própria peste durante a experiência cênica de oferecer aos espectadores meu corpo diferenciado em um ato de sacrifício, pois, como descreve Sylvère Lotringer (2018, p. 265266, grifo do autor):

O Teatro da Crueldade é a experiência da morte em vida. O teatro de Felipe Monteiro é vivo porque está vivo em face da morte e da doença. Não é algo que ele poderia colocar em sua face, ou em seu corpo, como uma máscara, mas é um com o seu corpo. Sua crueldade não é só um ato, mas um ato de fé. No parque quando ele celebra sua crueldade, ninguém pode deixar a cena rindo dele, como alguns fizeram com Artaud, que acabou performando perante um anfiteatro vazio. Felipe Monteiro transportou seu palco para um lugar público e a cena é tão conflitante que ninguém tem coragem de sair. Seu corpo é a peste e todos percebem de pronto que não é um ato, mas é real. E mesmo assim é mais do que real uma vez que insinua a si mesmo na mente das pessoas enquanto, de forma análoga ao regicídio, ele olha a si mesmo performando publicamente seu teatro privado de crueldade, deixando seu público transitório incapaz de decidir se testemunharam algo muito obsceno de ser visto, ou o derradeiro ato de bravura, que é sua própria deterioração física.

\section{Reliquiarium experientiis}

A terceira performance, Reliquiarium experientiis, foi apresentada em 24 de novembro de 2014 no Largo de São Francisco (Pelourinho), em Salvador (BA). Essa cena se fez a partir de um movimento de ruptura que objetivou dessacralizar a arte, tirando-a de sua função elitista, especialmente pela vontade de fazer arte fora dos muros da Ufba.

Em Reliquiarium experientiis, fiquei sentado e imóvel na cadeira de rodas durante uma hora, vestido com um figurino que fazia alusão às vestimentas religiosas e com os pés descalços. Coloquei um livro a minha frente e pendurei um banner com a frase "Escreva no livro o que você sente e/ou pensa ao me ver" em quatro idiomas (português, inglês, francês e espanhol). 


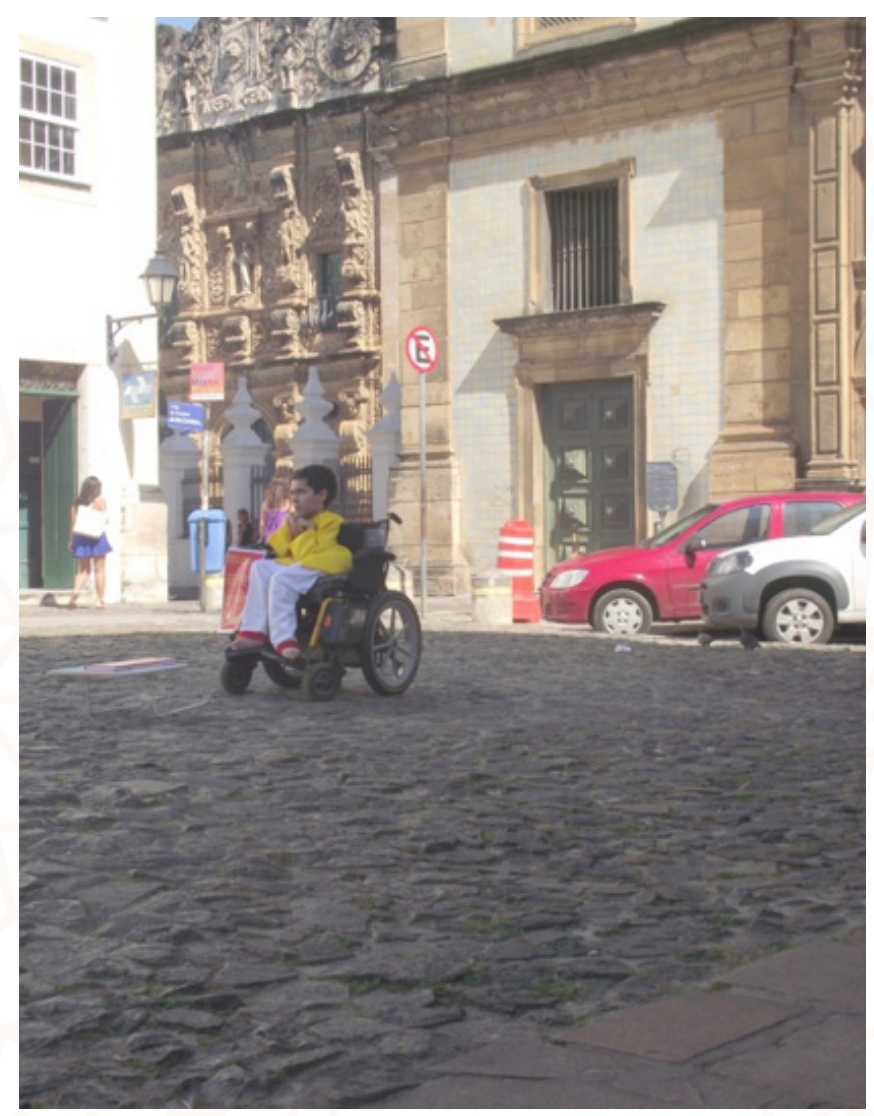

Figura 3 - Performance Reliquiarium experientiis Foto: Carlos Alberto Ferreira (2014)

Poucas pessoas realizaram o pedido feito no banner. Vejamos algumas frases escritas no livro:

Eu vejo uma pessoa frágil, mas com coragem de mostrar suas fragilidades. Me faz questionar o que é considerado como frágil; corpo ou espírito? (Camila Freitas)

A $1^{\text {a }}$ imagem: um santo / A $2^{\underline{a}}$ imagem: 0 pagador de promessas. (Olívia Camboim)

Então, o que é o corpo isolado? Qual sua noção há em ver o outro? E a imobilidade? Uma vida ser. Uma vida outra. É a minha, que não é a sua vida! Vida, Vide! IDA, DAVI. Filho ser. VIDA. (Carlos Alberto Ferreira)

EU QUERIA VER MINHA FILHA SE ESTÁ Bem (Telma dos Santos)

Minha primeira impressão é admirar a coragem para realizar esse trabalho. Nem todos os artistas são capazes de tamanha entrega. 
O impacto está, para mim, em ver a expressão artística em tudo que o cerca e principalmente na corporificação dessa arte. Sinto-me admirado e orgulhoso! (Gildon Oliveira)

Compreendi em Reliquiarium experientiis que, se não tivesse o corpo diferenciado, poderia participar normalmente das relações sociais, do cotidiano; mas, como apresento singulares características corporais que fogem aos padrões normativos da sociedade, meu corpo diferenciado acaba despertando as atenções alheias e, consequentemente, os outros esquecem que sou um ser humano como outro qualquer.

Não cabe à performance ser benemérita ou humanitária, pois o seu humanitarismo é realizado em permanentes entrecruzamentos com a vida, posto que não se isenta de questionar as problemáticas culturais e de outras circunstâncias em que está inserida. Mesmo não sendo uma arte definitivamente política, a performance executa seus artivismos através das problemáticas latentes de seus feitores, entre eles os performers com corpos diferenciados. Sendo insurgente, o performer torna-se um gerador de insurgências políticas, artísticas, sociais, pessoais, bem como de alteridades, porque legitima através do artivismo modos de existência pregnantes, que denunciam, subvertem e transgridem os padrões normativos instaurados na sociedade contemporânea brasileira.

\section{Referências bibliográficas}

ALCÁZAR, J. Performance: un arte del yo: autobiografía, cuerpo e identidad. México, DF: Siglo XXI, 2014.

ARTAUD, A. $O$ teatro e seu duplo. São Paulo: Martins Fontes, 2006.

FERNANDES, C. O corpo em movimento: o sistema Laban/Bartenieff na formação e pesquisa em artes cênicas. São Paulo: Annablume, 2006.

GOFFMAN, K.; JOY, D. Contracultura através dos tempos: do mito de Prometeu à cultura digital. Rio de Janeiro: Ediouro, 2007.

LOTRINGER, S. Contemplar o sofrimento. In: OLIVEIRA, F. H. M.; SALLES, N. (org.).

Corpos diferenciados em performance. São Paulo: Fonte Editorial, 2018. p. 263268.

MÈREDIEU, F. No limiar do corpo: metamorfoses e linhas de fuga: de Antonin Artaud às expressões contemporâneas. In: OLIVEIRA, F. H. M.; SALLES, N. (org.). 
Corpos diferenciados em performance. São Paulo: Fonte Editorial, 2018. p. 245262.

OLIVEIRA, F. H. M. Corpos diferenciados: a criação da performance "Kahlo em mim eu e(m) Kahlo". Maceió: Edufal, 2013.

OLIVEIRA, F. H. M. Subjetividade(s) e(m) performance: corpo, diferença e artivismo. 2018. Tese (Doutorado em Artes Cênicas) - Faculdade de Artes Cênicas, Universidade Federal da Bahia, Salvador, 2018.

OLIVEIRA, F. H. M.; SALLES, N. (org.). Corpos diferenciados em performance. São Paulo: Fonte Editorial, 2018.

PHELAN, P. Unmarked: the politics of performance. London: Routledge, 1993.

TAYLOR, D. Performance. Buenos Aires: Asuntos Impresos, 2012.

TAYLOR, D.; FUENTES, M. A. (ed.). Estudios avanzados de performance. México, DF: Fondo de Cultura Económica; New York: Instituto Hemisférico de Performance y Política, 2011.

Recebido em 02/02/2019

Aprovado em 19/09/2019

Publicado em 09/03/2020 